\title{
Chemical Composition and Bioactivity of Essential Oil of Atalantia guillauminii against Three Species Stored Product Insects
}

\author{
Kai Yang ${ }^{1}$, Chun-Xue You ${ }^{1}$, Cheng-Fang Wang ${ }^{1,2 *}$, Ning Lei ${ }^{3}$, Shan-Shan Guo ${ }^{1}$, \\ Zhu-Feng Geng ${ }^{4}$, Shu-Shan $\mathrm{Du}^{1 *}$, Ping $\mathrm{Ma}^{3}$ and Zhi-Wei Deng ${ }^{4}$ \\ ${ }^{1}$ Beijing Key Laboratory of Traditional Chinese Medicine Protection and Utilization, Beijing Normal University, No. 19, Xinjiekouwai Street, (Beijing \\ 100875, CHINA) \\ ${ }^{2}$ Key Laboratory of Radiological Protection and Nuclear Emergency Chinese Center for Disease Control and Prevention, (Beijing 100088, \\ CHINA) \\ ${ }^{3}$ Department of Pharmacy General Hospital of Second Artillery, PLA, Haidian District, (Beijing 100088, CHINA) \\ ${ }^{4}$ Analytical and Testing Center, Beijing Normal University, Haidian District, (Beijing 100875, CHINA)
}

\begin{abstract}
The toxic and repellent activities of the essential oil extracted from the leaves of Atalantia guillauminii Swingle were evaluated against three stored product insects, red flour beetles (Tribolium castaneum), cigarette beetles (Lasioderma serricorne) and booklice (Liposcelis bostrychophila). The essential oil obtained by hydrodistillation was investigated by GC-MS. The main constituents of the essential oil were $\beta$-thujene (27.18\%), elemicin (15.03\%), eudesma-3, 7(11)-diene $(9.64 \%)$, followed by (-)-4-terpeniol $(6.70 \%)$ and spathulenol $(5.25 \%)$. The crude oil showed remarkable contact toxicity against $T$. castaneum, $L$. serricorne adults and $L$. bostrychophila with $\mathrm{LD}_{50}$ values of $17.11,24.07 \mu \mathrm{g} / \mathrm{adult}$ and $55.83 \mu \mathrm{g} / \mathrm{cm}^{2}$ respectively and it also displayed strong fumigant toxicity against $T$. castaneum, $L$. serricorne adults with $L C_{50}$ values of 17.60 and $12.06 \mathrm{mg} / \mathrm{L}$ respectively, while weak fumigant toxicity against $L$. bostrychophila with a $\mathrm{LC}_{50}$ value of $16.75 \mathrm{mg} / \mathrm{L}$. Moreover, the essential oil also exhibited the same level repellency against the three stored product insects, relative to the positive control, DEET. At the same concentrations, the essential oil was more repellent to $T$. castaneum than to $L$. serricorne. Thus, the essential oil of $A$. guillauminii may be potential to be developed as a new natural fumigant/repellent in the control of stored product insects.
\end{abstract}

Key words: A. guillauminii, T. castaneum, L. serricorne, L. bostrychophila, bioactivity, essential oil composition

\section{INTRODUCTION}

Coleopterans have global importance in grain storage and industrial food production and can cause damage to the appearance of products as well as weight loss and reduced nutrient levels, rendering products unfit for human consumption ${ }^{1)}$. The red flour beetle(Tribolium castaneum Herbst) (Coleoptera: Tenebrionidae) is worldwidely distributed and among the most economically important stored product pests ${ }^{2}$. Infestations can also result in elevated temperature and moisture conditions that lead to an accelerated growth of molds, including toxigenic species $^{3)}$. Lasioderma serricorne Fabricius (Fabricius, 1792) (Coleoptera: Anobiidae), variously known as the cigarette beetle or the tobacco beetle, is cosmopolitan and occurs frequently in tropical and subtropical areas. This insect is usually found in perishable food products such as cereals, legumes, tobacco, tobacco products and traditional Chinese medicinal materials in warehouses ${ }^{4}$. The booklouse (Liposcelis bostrychophila Badonnel) (Psocoptera) is an important emerging pest of stored products. It feed on a wide variety of foods, but they are particularly associated with amylaceous products, such as grain and flour ${ }^{5,6)}$. The three stored product insects were also widespread in traditional Chinese medicinal materials.

Abbreviations: A. guillauminii: Atalantia guillauminii; $\boldsymbol{T}$. castaneum: Tribolium castaneum; L. serricorne: Lasioderma serricorne; L. bostrychophila: Liposcelis bostrychophila; RI: Retention Index; MS: mass spectrum

\footnotetext{
*Correspondence to: Shu-Shan Du, State Key Laboratory of Earth Surface Processes and Resource Ecology, Beijing Normal University, Haidian District, Beijing 100875, CHINA; Cheng-Fang Wang, China CDC Key Laboratory of Radiological Protection and Nuclear Emergency, National Institute for Radiological Protection, Chinese Center for Disease Control and Prevention, Beijing 100088, CHINA E-mail: dushushan@bnu.edu.cn; wangchengfang@mail.bnu.edu.cn
} Accepted June 22, 2015 (received for review June 4, 2015) 
Currently, control of stored product insects relies heavily on the use of synthetic insecticides and fumigants, which has led to problems such as disturbance of the environment, increasing application costs, pest resurgence, pest resistance to pesticides and lethal effects on non-target organisms in addition to direct toxicity to the users ${ }^{7,8)}$. Thus, there is a considerable interest in developing natural products which are relatively less damaging to mammalian health and the environment than existing conventional pesticides, and expected to be used as alternatives to nonselective synthetic pesticides to control the pests in the fields of medical and food security. In recent years, the researchers working in different fields have been concentrating their efforts on the search for natural products as alternatives to conventional insecticides and fumigants, as well as the re-evaluation of traditional botanical pest control agents $^{9,10)}$. Essential oils or their constituents may be ideal alternatives. Investigations have confirmed that some plant essential oils not only repel insects, but possess contact and fumigant toxicity against stored product pests as well as exhibited feeding inhibition or harmful effects on the reproductive system of insects ${ }^{11)}$. In addition, antibacterial and nematicidal antivities of essential oils have been reported $^{12-18)}$.

During the screening program for new agrochemicals from Chinese medicinal herbs and wild plants, the essential oil of Atalantia guillauminii leaves was found to possess strong insecticidal toxicity against the stored product insects, T. castaneum, L. serricorne and L. bostrychophila. Atalantia is a genus of about 17 species of flowering plants in the family Rutaceae, native to tropics and subtropics regions of Aisa ${ }^{19)}$. Many species of Atalantia, such as $A$. buxifolia, A. monophylla, A. racemosa and $A$. wightii, were used in traditional medicine. For example, $A$. buxifolia have long been used in traditional Chinese medicine for the treatment of cough, stomachache, hernia, rheumatism, hemiplegia, snakebite and traumatic injury ${ }^{20}$. A. monophylla possesses the same effect as A. buxifolia and also used for the treatment of antispasmodic, itch and other skin complaints ${ }^{21}$. Moreover, they all have antifungal, antioxidant activities, anti-allergic, antihepatotoxic, antiinflammatory, antimalarial, antimicrobial, antiviral, cytotoxic and insecticidal activities against Helicoverpa armigera, Spodoptera litura and so on ${ }^{22-27)}$. However, there is no report on medicinal use of A. guillauminii. A. guillauminii is a dungarunga distributed in Yunnan Province of China ${ }^{19)}$. In addition, a literature survey has shown that there is no report on the volatile constituents and insecticidal activity of A. guillauminii. Here, the chemical constituents and insecticidal activities of the essential oil of $A$. guillauminii leaves were investigated against stored product insects for the first time.

\section{EXPERIMENTAL PROCEDURES}

\subsection{Material}

2.1.1 Insects

Red flour beetles (T. castaneum), cigarette beetles ( $L$. serricorne) and booklouse (L. bostrychophila) were obtained from laboratory cultures maintained in the dark in incubators at $29-30^{\circ} \mathrm{C}$ and $70-80 \%$ relative humidity $(\mathrm{RH})$. The red flour beetles and cigarette beetles were reared on wheat flour mixed with yeast $(10: 1, \mathrm{w} / \mathrm{w})$ at $12-13 \%$ moisture content while the booklouse were reared on a 1:1:1 mixture, by mass, of milk powder, active yeast and flour. The unsexed adults beetles/booklouse used in all the experiments were about 1-2 weeks old. All containers housing insects and the petri dishes used in experiments were made escape proof with a coating of polytetrafluoroethylene(Fluon).

\subsubsection{Plant}

Fresh leaves $(1.3 \mathrm{~kg})$ of Atalantia guillauminii were harvested in 2011 from Xishuangbanna (northern latitude: $21^{\circ} 08^{\prime} \sim 22^{\circ} 36^{\prime}$; east longitude: $99^{\circ} 56^{\prime} \sim 101^{\circ} 50^{\prime}$ ) (Yunnan Province, China). The leaves were air dried for 1 week and ground to a powder. The plant species was identified and voucher specimens (BNU-dushushan- 2011-0612-24) were deposited at the Herbarium of College of Resources Science and Technology, Beijing Normal University (Beijing, China).

\subsection{Extraction of Essential oil}

The ground powder of A. guillauminii (2.0 kg) was subjected to hydrodistillation using a modified Clevenger-type apparatus for $10 \mathrm{~h}$ and extracted with $n$-hexane. Anhydrous sodium sulphate was used to remove water after extraction. The essential oil was stored in an airtight container in a refrigerator at $4^{\circ} \mathrm{C}$.

\subsection{Analysis of Essential Oil}

Components of the essential oil of A. guillauminii were separated and identified by using Bruker-320 gas chromatography/mass spectrometry (GC/MS) and equipped with a flame ionization detector and a capillary column with VF-5 $(30 \mathrm{~m} \times 0.25 \mathrm{~mm} \times 0.25 \mu \mathrm{m})$. The GC settings were as follows: The initial oven temperature was held at $50^{\circ} \mathrm{C}$ for 4 min and ramped at $10^{\circ} \mathrm{C} / \mathrm{min}$ to $290^{\circ} \mathrm{C}$ for $17 \mathrm{~min}$. The injector temperature was maintained at $250^{\circ} \mathrm{C}$. The samples $(1 \mu \mathrm{L}$, dilute to $1 \%$ with hexane) were injected neat, with a split ratio of 1:60. The carrier gas was helium at flow rate of $1 \mathrm{~mL} / \mathrm{min}$. Spectra were scanned from 45 to $650 \mathrm{~m} / \mathrm{z}$ at 2 scans/s. Most constituents were identified by gas chromatography by comparison of their retention indices with those of the literature or with those of authentic compounds available in our laboratories. The retention indices were determined in relation to a homologous series of $n$-alkanes $\left(\mathrm{C}_{8}-\mathrm{C}_{24}\right)$ under the same operating conditions. Further identification was made by comparison of their 
mass spectra with those stored in NIST 05 (Standard Reference Data, Gaithersburg, MD, USA) and Wiley 275 libraries (Wiley, New York, NY, USA) or with mass spectra from literature $^{28-30)}$. Component relative percentages were calculated based on GC peak areas, without using correction factors.

\subsection{Contact Toxicity}

The contact toxicity of the essential oil against T. castaneum and $L$. serricorne adults was measured by using topical application as described by Liu and $\mathrm{Ho}^{5)}$. Serial dilutions of essential oil (10-1.97\% (v/v) for T. castaneum and L. serricorne; five concentrations) were prepared in $n$ hexane. Preliminary experiments were conducted to determine appropriate ranges of test concentrations. Aliquots $(0.5 \mu \mathrm{L})$ of the dilutions were applied topically to the dorsal thorax of the insects. Controls were established using $n$ hexane. Both treated and control insects were then transferred to glass vials (ten insects per vial) with culture media and kept in incubators at $29-30^{\circ} \mathrm{C}$ and $70-80 \%$ RH. Mortality of insects was observed daily until end-point mortality was rearched $24 \mathrm{~h}$ after treatment. The experiments were repeated three times. While the contact toxicity of the essential oil against $L$. bostrychophila was also tested as described $^{5)}$. A $5.5 \mathrm{~cm}$ diameter filter paper was treated with $300 \mu \mathrm{L}$ of the solution of the essential oil. The filter paper after treated with solid glue was placed in a $5.5 \mathrm{~cm}$ diameter petri dish and 10 booklice were put on the filter paper. A cover was put and all the petri dishes were kept in incubators. $n$-Hexane was used as a negative control. Five concentrations (in $n$-hexane) and five replicates of each concentration were used. Mortality of insects was observed after $24 \mathrm{~h}$. The $\mathrm{LD}_{50}$ values were calculated by using Probit analysis $^{31}$.

\subsection{Fumigant Toxicity}

Serial dilution of the essential oil were prepared in $n$ hexane. Filter papers (Whatman Cat. No. 1001020, diameter $2 \mathrm{~cm}$ ) were impregnated with $10 \mu \mathrm{L}$ of an appropriate concentration (10-1.97\% (v/v) for T. castaneum and L. serricorne; five concentrations) of essential oil and each was placed on the underside of the screw cap of a glass vial (diameter $2.5 \mathrm{~cm}$, height $5.5 \mathrm{~cm}$, volume $25 \mathrm{~mL}$ ). Preliminary experiments were conducted to determine appropriate ranges of test concentrations. Fluon was used inside each glass vial to prevent insect contact with the treated filter paper. The solvent was allowed to evaporate for $20 \mathrm{~s}$ was before the cap was screwed tightly on each glass vial containing ten insects. Preliminary experiments demonstrated that $20 \mathrm{~s}$ was sufficient for solvent evaporation. $n$-Hexane was used as a control. Five replicates were carried out for all treatments and controls, which were incubated for $24 \mathrm{~h}$. The experiments were repeated three times. While the fumigant activity of the essential oil against $L$. bostrychophi- $l a$ was tested as described ${ }^{5}$. A filter paper strip $(3.5 \times 1.5$ $\mathrm{cm}$ ) treated with $10 \mu \mathrm{L}$ of an appropriate concentration of the test essential oil. The impregnated filter paper was then placed in the bottom cover of a $250 \mathrm{~mL}$ volume of glass bottle. Ten unsexed adults of the booklouse in a small glass bottle $(8 \mathrm{~mL})$ were put into the glass bottle and exposed for $24 \mathrm{~h}$. Five concentrations of the oil were used in the experiments and each concentration with five replicates. $n$-Hexane was used as a negative control. The $\mathrm{LC}_{50}$ values were calculated by using Probit analysis ${ }^{31)}$.

\subsection{Repellency Tests}

The repellent effects of the essential oil against $T$. castaneum, L. serricorne and $L$. bostrychophila were assessed by using assays on petri dishes ${ }^{32}$. Petri dishes $9 \mathrm{~cm}$ in diameter were used to confine beetles during the experiment for T. castaneum and L. serricorne. The essential oil of $A$. guillauminii were prepared in $n$-hexane $(78.63,15.73$, $3.15,0.63$ and $0.13 \mathrm{~nL} / \mathrm{cm}^{2}$ ), and absolute $n$-hexane was used as the control. Filter paper $9 \mathrm{~cm}$ in diameter was cut in half and $500 \mu \mathrm{L}$ of each concentration was applied separately to half of the filter paper as uniformly as possible with a micropipette. The other half (control)was treated with $500 \mu \mathrm{L}$ of absolute $n$-hexane. Both the treated half and the control half were then air-dried to evaporate the solvent completely $(30 \mathrm{~s})$. A full disk was carefully remade by attaching the tested half to the negative control half with tape. Each reassembled filter paper after treatment with solid glue was placed in a petri dish with the seam oriented in one of four randomly selected different directions to avoid any insecticidal stimuli affecting the distribution of insects. Twenty insects were released in the center of each filter paper disk, and a cover was placed over the petri dish. Five replicates were used, and the experiment was repeated three times. Counts of the insects present on each strip were made after 2 and $4 \mathrm{~h}$. The percent repellency $(\mathrm{PR})$ of each volatile oil was then calculated using the formula

$$
\operatorname{PR}(\%)=\left[\left(\mathrm{N}_{\mathrm{c}}-\mathrm{N}_{\mathrm{t}}\right) /\left(\mathrm{N}_{\mathrm{c}}+\mathrm{N}_{\mathrm{t}}\right)\right] \times 100
$$

Where $\mathrm{N}_{\mathrm{c}}$ is the number of insects present in the negative control half and $\mathrm{N}_{\mathrm{t}}$ is the number of insects present in the treated half. The averages were then assigned to different classes $(0$ to $\mathrm{V}$ ) using the following scale (percentage repellency ${ }^{33)}$. Class, \% repellency: $0,>0.01$ to $<0.1 ;$ I, 0.1 20.0; II, 20.1-40.0; III, 40.1-60.0; IV, 60.1-80.0; and V, 80.1100.

As for the booklouse, petri dishes and filter papers were changed to $6 \mathrm{~cm}$ in diameter and the concentration of the oil used in the experiments were $31.58,6.32,1.26,0.25$, $0.05 \mathrm{~nL} / \mathrm{cm}^{2}$. The half filter paper was treated with $150 \mu \mathrm{L}$ of the solution. As a positive control, a commercial repellent $\operatorname{DEET}(\mathrm{N}, \mathrm{N}$-diethyl-3-methyl-benzamide), was used under the conditions as the oil. Analysis of variance 
(ANOVA) and Tukey's test were conducted by using SPSS statistics 20 for Windows 2007. Percentage was subjected to an arcsine square-root transformation before ANOVA and Tukey's tests.

\section{RESULTS AND DISCUSSION}

\subsection{Chemical Constituents of Essential Oil}

The essential oil yield of A. guillauminii was $0.15 \%$ (v/ w) and the density of the concentrated essential oil was determined as $0.90 \mathrm{~g} / \mathrm{mL}$. The results of GC/MS of A. guillauminii essential oil are presented in Table 1. 49 components which were accounted for $99.51 \%$ of the total oil were identified (Table 1). The main components in the essential oil of A. guillauminii were $\beta$-thujene (27.18\%), elemicin (15.03\%), eudesma-3, 7(11)-diene (9.64\%), followed by (-)-4-terpeniol (6.70\%), spathulenol (5.25\%) and elixene (3.43\%) . Among the 49 compounds, 18 components belonged to monoterpenoids, corresponding to $45.81 \%$ of the whole oil, while 27 constituents were sesquiterpenoids (36.53\% of the crude essential oil) and others were accounted for $17.17 \%$ of the total oil. A literature survey has shown that the chemical composition of $A$. guillauminii essential oil was calculated for the first time. However, the constituents of essential oils derived from other species of Atalantia have been reported. Das and Swamy revealed that the major compounds of A. monophylla essential oil collected from Nagamalai hills of Madurai district, Tamil Nadu were $\alpha$-asarone (28.82\%), sabinene (13.19\%), eugenol methyl ether(12.71\%), 1,2-di- methoxy-4-(2-methoxyethenyl) benzene (11.63\%) and $\beta$-pinene $(5.3 \%)^{34)}$. Ten compounds were identified by Manimaran et al. on essential oil from A. monophylla leaves collected from Narrtha hills, Pudukkottai and the major compounds identified in that study were methyl eugenol (36.46\%), sabinene $(24.89 \%)$ and elemicin $(24.61 \%)^{35)}$. It has been proved that there was variation in the chemical composition of essential oils collected in different areas. The difference in chemical constitution may be probably due to different environmental and genetic factors, different chemotypes and the nutritional status of the plants as well as other factors. Thus for the practical application of the essential oil as a novel fumigant/repellent, further studies on plant cultivation and essential oil standardization are needed because chemical composition of the essential oil varies greatly with the plant population.

\subsection{Contact Toxicity}

The crude essential oil of A. guillauminii leaves showed pronounced contact toxicity against $T$. castaneum, L. serricorne and L. bostrychophila with $\mathrm{LD}_{50}$ values of 17.11, $24.07 \mu \mathrm{g} /$ adult and $55.83 \mu \mathrm{g} / \mathrm{cm}^{2}$ respectively (Table 2 ). When compared with the positive control, pyrethrins, the essential oil demonstrated 65.8, 100 and 3.0 times less toxic against $T$. castaneum, $L$. serricorne adults and $L$. bostrychophila respectively. It showed that L. bostrychophila was the most susceptible to the contact toxicity of the essential oil of A. guillauminii and L. serricorne adults were more tolerant than $T$. castaneum adults. However, compared with the other essential oils in the literature, the essential oil of A. guillauminii leaves pos-

Table 1 Chemical constituents of essential oil derived from leaves of A. guillauminii.

\begin{tabular}{|c|c|c|c|c|}
\hline Peak no. & Compounds & $\mathrm{RI}^{\mathrm{a}}$ & $\% \mathrm{RA}^{\mathrm{b}}$ & Identification Methods $^{\mathrm{c}}$ \\
\hline 1 & $\alpha$-Thujene & 927 & 0.51 & MS, RI \\
\hline 2 & 1R- $\alpha$-Pinene & 931 & 1.94 & MS, RI, Co \\
\hline 3 & $\beta$-Thujene & 967 & 27.18 & MS, RI \\
\hline 4 & $\beta$-pinene & 981 & 0.85 & MS, RI \\
\hline 5 & $\alpha$-Phellandrene & 1005 & 0.21 & MS, RI \\
\hline 6 & o-Cymene & 1012 & 2.95 & MS, RI \\
\hline 7 & D-Limonene & 1014 & 0.63 & MS, RI \\
\hline 8 & $\alpha$-Terpinene & 1017 & 0.42 & MS, RI \\
\hline 9 & $\beta$-Phellandrene & 1030 & 2.04 & MS, RI \\
\hline 10 & $\gamma$-Terpinene & 1057 & 0.92 & MS, RI \\
\hline 11 & cis- $\beta$-Terpineol & 1060 & 0.19 & MS, RI \\
\hline 12 & Terpinolene & 1080 & 0.29 & MS, RI \\
\hline 13 & Linalool & 1094 & 0.17 & MS, RI \\
\hline 14 & cis-p-Menth-2-en-1-ol & 1126 & 0.38 & MS, RI \\
\hline 15 & trans-p-Menth-2-en-1-ol & 1140 & 0.14 & MS, RI \\
\hline
\end{tabular}


Table 1 Continued.

\begin{tabular}{|c|c|c|c|c|}
\hline Peak no. & Compounds & $\mathrm{RI}^{\mathrm{a}}$ & $\% \mathrm{RA}^{\mathrm{b}}$ & Identification Methods ${ }^{\mathrm{c}}$ \\
\hline 16 & Sabina ketone & 1160 & 0.27 & MS, RI \\
\hline 17 & (-)-4-Terpeniol & 1179 & 6.70 & MS, RI \\
\hline 18 & $\alpha$-Terpieol & 1191 & 0.23 & MS, RI \\
\hline 19 & cis-Piperitol & 1196 & 0.06 & MS, RI \\
\hline 20 & Elixene & 1313 & 3.43 & MS, RI \\
\hline 21 & Copaene & 1374 & 0.24 & MS, RI \\
\hline 22 & $\beta$-Cubebene & 1392 & 0.40 & MS, RI \\
\hline 23 & $\beta$-Elemene & 1393 & 0.88 & MS, RI \\
\hline 24 & Methyleugenol & 1401 & 1.57 & MS, RI, Co \\
\hline 25 & Viridiflorene & 1403 & 0.78 & MS, RI \\
\hline 26 & Caryophyllene & 1420 & 1.28 & MS, RI, Co \\
\hline 27 & $\alpha$-Bergamotene & 1433 & 0.46 & MS, RI \\
\hline 28 & $\alpha$-Guaiene & 1442 & 0.21 & MS, RI \\
\hline 29 & $(+)$-Aromadendrene & 1448 & 0.15 & MS, RI \\
\hline 30 & $\alpha$-Caryophyllene & 1454 & 0.40 & MS, RI \\
\hline 31 & (-)-Alloaromadendrene & 1458 & 0.65 & MS, RI \\
\hline 32 & $\alpha$-Bulnesene & 1501 & 0.74 & MS, RI \\
\hline 33 & $\beta$-Guaiene & 1506 & 0.27 & MS, RI \\
\hline 34 & Calamenene & 1511 & 0.24 & MS, RI \\
\hline 35 & Cadinene & 1519 & 0.67 & MS, RI \\
\hline 36 & Eudesma-3,7(11)-diene & 1536 & 9.64 & MS, RI \\
\hline 37 & Hedycaryol & 1550 & 0.46 & MS, RI \\
\hline 38 & Elemicin & 1554 & 15.03 & MS, RI \\
\hline 39 & $\alpha$-Cedrene epoxide & 1562 & 0.74 & MS, RI \\
\hline 40 & Spathulenol & 1578 & 5.25 & MS, RI \\
\hline 41 & Caryophyllene oxide & 1583 & 1.12 & MS, RI, Co \\
\hline 42 & Diepicedrene-1-oxide & 1588 & 0.19 & MS, RI \\
\hline 43 & Viridiflorol & 1590 & 1.96 & MS, RI \\
\hline 44 & Guaiol & 1602 & 2.14 & MS, RI \\
\hline 45 & $\gamma$-Eudesmol & 1621 & 2.78 & MS, RI \\
\hline 46 & $\beta$-Eudesmol & 1648 & 1.13 & MS, RI \\
\hline 47 & $\tau$-Muurolol & 1662 & 0.11 & MS, RI \\
\hline 48 & 2,3,4,5-tetramethyl-Tricyclo[3.2.1.02,7]oct-3-ene & 1680 & 0.30 & MS, RI \\
\hline \multirow[t]{5}{*}{49} & Epiglobulol & 1723 & 0.21 & MS, RI \\
\hline & Monoterpenoids & & 45.81 & \\
\hline & Sesquiterpenoids & & 36.53 & \\
\hline & Others & & 17.17 & \\
\hline & Total & & 99.51 & \\
\hline
\end{tabular}

${ }^{a}$ Retention index (RI) as determined on an VF-5 MS column using a homologous series of $n$-hydrocarbons.

${ }^{\mathrm{b}}$ Relative area (peak area relative to the total peak area).

${ }^{\mathrm{c}} \mathrm{MS}=$ mass spectrum, $\mathrm{Co}=$ co-injection with standard compound. 
Table 2 Toxicity of A. guillauminii essential oil against T. castaneum (TC), L. serricorne (LS) and L. bostrychophila (LB) adults.

\begin{tabular}{|c|c|c|c|c|c|}
\hline \multirow[b]{2}{*}{ Insect } & \multirow[b]{2}{*}{ Compound } & \multicolumn{2}{|c|}{ Fumigant toxicity } & \multicolumn{2}{|c|}{ Contact toxicity } \\
\hline & & $\begin{array}{c}\mathrm{LC}_{50} \\
\text { (mg/L air) }\end{array}$ & $\begin{array}{c}95 \% \text { confidence } \\
\text { limits }\end{array}$ & $\begin{array}{c}\mathrm{LD}_{50} \\
(\mu \mathrm{g} / \mathrm{adult}) /\left(\mu \mathrm{g} / \mathrm{cm}^{2}\right)\end{array}$ & $\begin{array}{c}95 \% \text { confidence } \\
\text { limits }\end{array}$ \\
\hline \multirow{3}{*}{$\mathrm{TC}$} & Crude oil & 17.60 & $15.83-19.63$ & 17.11 & $14.57-19.56$ \\
\hline & Pyrethrinsa & - & - & 0.26 & $0.22-0.30$ \\
\hline & MeBrb & 1.75 & - & - & - \\
\hline \multirow{3}{*}{ LS } & Crude oil & 12.06 & $9.97-14.06$ & 24.07 & $19.97-27.93$ \\
\hline & Pyrethrinsa & - & - & 0.24 & $0.16-0.35$ \\
\hline & Phosphinea & $9.23 \times 10^{-3}$ & $7.13-11.37 \times 10^{-3}$ & - & - \\
\hline \multirow{3}{*}{ LB } & Crude oil & $>16.75$ & - & 55.83 & $51.05-61.20$ \\
\hline & Pyrethrinsc & - & - & 18.72 & $17.60-19.92$ \\
\hline & Dichlorvosc & $1.35 \times 10^{-3}$ & - & - & - \\
\hline
\end{tabular}

${ }^{\mathrm{b}}$ Data from Liu and $\mathrm{Ho}^{33)}$; ${ }^{\mathrm{a}}$ Data from You et $a l .{ }^{50)}$; ${ }^{\mathrm{c}}$ Data from Yang et al. ${ }^{51)}$.

sessed stronger contact toxicity against T. castaneum adults, e.g. essential oils of Dracocephalum moldavica $\left.\left(\mathrm{LD}_{50}=18.28 \mu \mathrm{g} / \text { adult }\right)^{36}\right)$, Murraya exotica $\left(\mathrm{LD}_{50}=20.94\right.$ $\mu \mathrm{g} /$ adult $)^{37)}$, Evodia lepta $\left(\mathrm{LD}_{50}=166.94 \mu \mathrm{g} / \mathrm{adult}\right)^{38)}$. While the essential oil of $A$. guillauminii leaves also exhibited stronger contact toxicity against $L$. bostrychophila than the other reported oils, for example essential oils of Lonicera japonica $\left(\mathrm{LD}_{50}=64.04 \mu \mathrm{g} / \mathrm{cm}^{2}\right)^{5}$, Foeniculum vulgare $\left.\left(\mathrm{LD}_{50}=90.36 \mu \mathrm{g} / \mathrm{cm}^{2}\right)^{39}\right)$, Acorus calamus $\left(\mathrm{LD}_{50}=\right.$ $\left.100.21 \mu \mathrm{g} / \mathrm{cm}^{2}\right)^{40)}$, Curcuma wenyujin $\left(\mathrm{LD}_{50}=208.85 \mu \mathrm{g} /\right.$ $\left.\mathrm{cm}^{2}\right)^{41}$.

\subsection{Fumigant toxicity}

The crude essential oil also displayed strong fumigant toxicity against $T$. castaneum, $L$. serricorne with $\mathrm{LC}_{50}$ values of $17.60,12.06 \mathrm{mg} / \mathrm{L}$ air respectively while exhibited weak fumigant toxicity against $L$. bostrychophila $\left(\mathrm{LC}_{50}>\right.$ $16.75 \mathrm{mg} / \mathrm{L}$ air (Table 2). Fumigation plays a very important role in insect pest elimination in stored products. The fumigant activity $\left(\mathrm{LC}_{50}\right)$ of one of the currently used grain fumigants, methyl bromide, against T. castaneum adults is reported to be $1.75 \mathrm{mg} / \mathrm{mL}$ air. Compared with methyl bromide, the essential oil of A. guillauminii was 10 times less toxic to T. castaneum adults. Nevertheless, compared with the other essential oils in the literature, the essential oil of A. guillauminii leaves possessed stronger fumigant toxicity against $T$. castaneum adults, e.g. essential oils of Ostericum sieboldii $\left(\mathrm{LC}_{50}=20.92 \mathrm{mg} / \mathrm{mL}\right.$ air $\left.{ }^{42}\right)$, Evodia rutaecarpa $\left.\left(\mathrm{LC}_{50}=24.57 \mathrm{mg} / \mathrm{mL} \text { air }\right)^{43}\right)$, Artemisia vulgaris $\left(\mathrm{LC}_{50}=279.86 \mu \mathrm{L} / \mathrm{L} \text { air }\right)^{44)}$. Compared with phosphine $\left(\mathrm{LC}_{50}=9.23 \mu \mathrm{g} / \mathrm{L}\right.$ air $)$, the essential oil of A. guillauminii was $1.3 \times 10^{3}$ times less toxic to $L$. serricorne adults (Table 2). However the essential oil also showed stronger fumigant toxicity against $L$. serricorne adults, e.g. the essential oil of Agastache foeniculum $\left(\mathrm{LC}_{50}=21.565 \mu \mathrm{L} / \mathrm{L}\right.$ air ${ }^{45)}$. Moreover, considering that the currently used fumigants are synthetic insecticides, the fumigant activity of the essential oil of A. guillauminii is quite promising, showing its potential to be developed as possible natural fumigants for the control of stored product insects. Further studies are needed to assess the fumigant activity of the crude essential oil against other stored product insects at different life stages.

\subsection{Repellency}

In addition to contact and fumigant activities, the repellent effect of the essential oil of A. guillauminii against the three stored product insects was also investigated. The results are presented in Table 3 and 4. This essential oil strongly repelled all species of stored product insects, but the repellent effect was more marked on $T$. castaneum than on L. serricorne. Data showed that at the tested concentration of $0.63 \mathrm{~nL} / \mathrm{cm}^{2}$, the crude oil still showed moderate repellency ( $76 \%$ and $60 \%$ ) (class IV and class III) against the red flour beetle, T. castaneum adults at 2 and $4 \mathrm{~h}$ after exposure (Table 3 ). While no repellency of the positive control, DEET, but some insect attractant properties were observed at 0.63 and $0.13 \mathrm{~nL} / \mathrm{cm}^{2}$ at $4 \mathrm{~h}$ after exposure. What's more, at the other assayed concentrations, the essential oil of A. guillauminii exhibited strong repellency (class V) at 2 and $4 \mathrm{~h}$ after exposure (Table 3 ).

Compared with the positive control, DEET, the crude oil of $A$. guillauminii possessed the same level repellency against the cigarette beetle, L. serricorne at tested concentrations. At the assayed concentration of $78.63 \mathrm{~nL} / \mathrm{cm}^{2}$, the crude oil was strongly repellent (class V) at 2 and $4 \mathrm{~h}$ after exposure (Table 3 ). With the decreasing of the sample concentration, the repellent activity of the essential oil of A. guillauminii was decreased. When at $0.13 \mathrm{~nL} / \mathrm{cm}^{2}$, compared with the positive control, DEET (46\%, class III), 
Table 3 Pecentage repellency (PR) after two exposure times for the essential oil against $T$. castaneum (TC) and L. serricorne (LS) adults ${ }^{\mathrm{a}}$.

\begin{tabular}{|c|c|c|c|c|c|c|c|c|c|c|c|}
\hline \multirow{2}{*}{ Insect } & \multirow{2}{*}{ Compound } & \multicolumn{5}{|c|}{$2 \mathrm{~h}$} & \multicolumn{5}{|c|}{$4 \mathrm{~h}$} \\
\hline & & $78.63 *$ & $15.73^{*}$ & $3.15^{*}$ & $0.63 *$ & $0.13^{*}$ & $78.63 *$ & $15.73 *$ & $3.15^{*}$ & $0.63^{*}$ & $0.13 *$ \\
\hline \multirow{4}{*}{$\mathrm{TC}$} & \multirow{2}{*}{ Crude oil } & $98 \pm 3 a$ & $96 \pm 3 a$ & $82 \pm 10 a$ & $76 \pm 15 a$ & $40 \pm 10 \mathrm{a}$ & $100 \pm 0 \mathrm{a}$ & $94 \pm 6 a$ & $84 \pm 9 a$ & $60 \pm 11 a$ & $30 \pm 12 a$ \\
\hline & & V & V & V & IV & II & V & V & V & III & II \\
\hline & \multirow{2}{*}{ DEET } & $100 \pm 0 \mathrm{a}$ & $96 \pm 3 a$ & $74 \pm 16 a$ & $66 \pm 9 a$ & $18 \pm 16 b$ & $94 \pm 6 a$ & $80 \pm 10 a$ & $46 \pm 17 b$ & $-2 \pm 20 b$ & $-8 \pm 22 b$ \\
\hline & & V & V & IV & IV & I & V & IV & III & - & - \\
\hline \multirow{4}{*}{ LS } & \multirow{2}{*}{ Crude oil } & $84 \pm 7 a$ & $60 \pm 8 a$ & $42 \pm 11 \mathrm{a}$ & $24 \pm 7 a$ & $10 \pm 12 a$ & $82 \pm 9 a$ & $64 \pm 13 a$ & $62 \pm 8 \mathrm{a}$ & $60 \pm 8 \mathrm{a}$ & $16 \pm 17 \mathrm{a}$ \\
\hline & & V & III & III & II & I & $\mathrm{V}$ & IV & IV & III & I \\
\hline & \multirow{2}{*}{ DEET } & $88 \pm 7 a$ & $76 \pm 14 a$ & $28 \pm 7 b$ & $20 \pm 14 \mathrm{a}$ & $16 \pm 7 a$ & $98 \pm 4 a$ & $78 \pm 9 a$ & $58 \pm 16 \mathrm{a}$ & $56 \pm 14 \mathrm{a}$ & $46 \pm 7 b$ \\
\hline & & V & IV & II & I & I & $\mathrm{V}$ & IV & III & III & III \\
\hline
\end{tabular}

* Concentration $\left(\mathrm{nL} / \mathrm{cm}^{2}\right) ;{ }^{\text {a }}$ Means in the same column followed by the same letters do not differ significantly $(p<0.05)$ in ANOVA and Tukey's tests. PR was subjected to an arcsine square-root transformation before ANOVA and Tukey's tests.

Table 4 Percentage repellency (PR) after two exposure times for the essential oil against $L$. bostrychophila (LB) .

\begin{tabular}{|c|c|c|c|c|c|c|c|c|c|c|c|}
\hline \multirow{2}{*}{ Insect } & \multirow{2}{*}{ Compound } & \multicolumn{5}{|c|}{$2 \mathrm{~h}$} & \multicolumn{5}{|c|}{$4 \mathrm{~h}$} \\
\hline & & $31.58^{*}$ & $6.32 *$ & $1.26^{*}$ & $0.25^{*}$ & $0.05 *$ & $31.58^{*}$ & $6.32 *$ & $1.26^{*}$ & $0.25^{*}$ & $0.05^{*}$ \\
\hline \multirow{4}{*}{ LB } & Crudo oil & $90 \pm 9 a$ & $92 \pm 5 \mathrm{a}$ & $88 \pm 7 \mathrm{a}$ & $40 \pm 22 a$ & $22 \pm 15 \mathrm{a}$ & $92 \pm 5 \mathrm{a}$ & $88 \pm 8 \mathrm{a}$ & $82 \pm 5 a$ & $54 \pm 14 a$ & $38 \pm 15 a$ \\
\hline & Crude o1l & V & V & $\mathrm{V}$ & II & II & V & V & V & III & II \\
\hline & DFFT & $100 \pm 0 \mathrm{a}$ & $92 \pm 7 \mathrm{a}$ & $92 \pm 7 \mathrm{a}$ & $74 \pm 9 b$ & $30 \pm 10 \mathrm{a}$ & $96 \pm 7 \mathrm{a}$ & $90 \pm 10 a$ & $90 \pm 6 a$ & $72 \pm 19 b$ & $32 \pm 7 \mathrm{a}$ \\
\hline & DEEI & V & V & V & IV & II & V & V & V & IV & II \\
\hline
\end{tabular}

"Concentration $\left(\mathrm{nL} / \mathrm{cm}^{2}\right) ;{ }^{\text {a }}$ Means in the same column followed by the same letters do not differ significantly $(p<0.05)$ in ANOVA and Tukey's tests. PR was subjected to an arcsine square-root transformation before ANOVA and Tukey's tests.

the essential oil of A. guillauminii showed lesser repellency against the cigarette beetles ( $16 \%$, class I) at $4 \mathrm{~h}$ after exposure (Table 3).

At tested concentrations, compared with the positive control, the crude oil of A. guillauminii also showed the same level repellency against the booklice, L. bostrychophila at 2 and $4 \mathrm{~h}$ after exposure(Table 4 ). Moreover, at the assayed concentrations of $31.58,6.32,1.26 \mathrm{~nL} / \mathrm{cm}^{2}$, the oil exhibited strongly repellent (class V) against the booklice at 2 and $4 \mathrm{~h}$ after exposure, while at the lowest tested concentration of $0.05 \mathrm{~nL} / \mathrm{cm}^{2}$, class II repellency against the booklice still was observed at 2 and $4 \mathrm{~h}$ after exposure (Table 4). Many essential oils were evaluated for repellency against insects ${ }^{46)}$. In China, the essential oils derived from spice and Chinese medicinal herbs were also evaluated for insecticidal activity and repellency against insects $^{40,41,47-49)}$. In this article, we report the insecticidal and repellent activities of the essential oil of A. guillauminii for the frist time. Above all, the essential oil of A. guillauminii possessed strong repellency against the three stored product insects. These findings, considered together, suggest that the essential oil of A. guillauminii show potential for development as natural repellents for stored product.

\section{CONCLUSION}

Based on mass screening, essential oil of A. guillauminii leaves was examined for their bioactivities against red flour beetles T. castaneum, cigarette beetles $L$. serricorne and booklice $L$. bostrychophila. The essential oil possessed strong contact and fumigant toxicity against the three stored product insects. Furthermore, the essential oil also exhibited strongly repellence against the three stored product insects. These findings suggest that the essential oil show potential for development as a natural fumigant and repellent for stored products.

\section{ACKNOWLEDGEMENT}

This project was supported by National Natural Science Foundation of China(No. 81374069), Beijing Municipal Natural Science Foundation(No. 7142093) and Fundamental Research Funds for the Central Universities. We thank Dr. Liu Q.R. from the College of Life Sciences, Beijing Normal University, Beijing 100875, for the identification of the investigated medicinal herb.

\section{REFERENCES}

1) Nansen, C.; Subramanyam, B.; Roesli, R. Characteriaing spatial distribution of trap captures of beetles in 
retail pet stores using SADIE® software. J. Stored Prod. Res. 40, 471-483(2004).

2) Garcìa, M.; Donael, O. J.; Ardanaz, C. E.; Tonn, C. E.; Sosa, M. E. Toxic and repellent effects of Baccharis salicifolia essential oil on Tribolium castaneum. Pest Manag. Sci. 61, 612-618(2005).

3) Magan, N.; Hope, R.; Cairns, V.; Aldred, D. Post-harvest fungal ecology: impact of fungal growth and mycotoxin accumulation in stored grain. Eur. J. Plant Pathol. 109, 723-730 (2003).

4) Papadopoulou, S. C.; Athanassiou, C. G. Lariophagus distinguendus (F.) (Hyme., Chalcidoidea, Pteromalidae), an ectoparasitoid of Lasioderma serricorne(F.) (Col. Anobiidae), found for the first time in tobacco stores in Greece. J. Pest Sci. 77, 183-184(2004).

5) Zhou, H. Y.; Zhao, N. N.; Du, S. S.; Yang, K.; Wang, C. F.; Liu, Z. L.; Qiao, Y. J. Insecticidal activity of the essential oil of Lonicera japonica flower buds and its main constituent compounds against two grain storage insects. J. Med. Plants Res. 6, 912-917 (2012).

6) Phillips, T. W.; Throne, J. E. Biorational approaches to managing stored-product insects. Annu. Rev. Entomol. 55, 375-397 (2010).

7) Shaaya, E.; Kostjukovski, M.; Eilberg, J.; Sukprakarn, C. Plant oils as fumigants and contact insecticides for the control of stored-product insects. J. Stored Prod. Res. 33, 7-15 (1997).

8) Tapondjoua, A. L.; Adlerb, C.; Fontemc, D. A.; Boudaa, H.; Reichmuth, C. Bioactivity of cymol and essential oils of Cupressus sempervirens and Eucalyptus saligna against Sitophilus zeamais Motschulsky and Tribolium confusum du Val. J. Stored Prod. Res. 41, 91-102 (2005).

9) Ismam, M. B. Plant essential oils for pest and disease management. Crop Prot. 19, 603-608(2000).

10) Isman, M. B. Botanical insecticides, deterrents, and repellents in modern agriculture and an increasingly regulated world. Annu. Rev. Entomol. 51, 45-66 (2006).

11) Rajendran, S.; Srianjini, V. Plant products as fumigants for stored-product insects control. J. Stored Prod. Res. 44, 126-135 (2008).

12) Khalighi-Sigaroodi, F.; Hadjiakhoondi, A.; Shahverdi, A.R.; Mozaffaricen, V. A.; Shafiee, A. Composition and antimicrobial activity of the essential oil of Ferulago bernardii Tomk. and M. Pimen. Daru J. Pharm. Sci. 13, 100-104 (2005).

13) Dehghan, G.; Solaimanian, R.; Shahverdi, A. R.; Amin, G.; Abdollahi, M.; Shafiee, A. Chemical composition and antimicrobial activity of essential oil of Ferula szovitsiana D. C. Flavour Frag. J. 22, 224-227 (2007).

14）Wang, J. H.; Zhao, J. L.; Liu, H.; Zhou, L. G.; Liu, Z. L.; Han, J. G.; Zhu, Y.; Yang, F. Y. Chemical analysis and biological activity of the essential oils of two Valerianaceous species from China: Nardostachys chinensis and Valeriana officinalis. Molecules 15, 6411-6422 (2010).

15) Wang, J. H.; Liu, H.; Zhao, J. L.; Gao, H. F.; Zhou, L.; Liu, Z. L.; Chen, Y. Q.; Sui, P. Antimicrobial and antioxidant activities of the root bark essential oil of Periploca sepium and its main component 2-Hydroxy-4methoxybenzaldehyde. Molecules 15, 5807-5817 (2010).

16) Bai, C. Q.; Liu, Z. L.; Liu, Q. Z. Nematicidal constituents from the essential oil of Chenopodium ambrosioides aerial parts. E-J. Chem. 8, 143-148(2011).

17) Li, H. Q.; Bai, C. Q.; Chu, S. S.; Zhou, L.; Du, S. S.; Liu, Z. L.; Liu, Q. Z. Chemical composition and toxicities of the essential oil derived from Kadsura heteroclita stems against Sitophilus zeamais and Meloidogyne incognita. J. Med. Plants Res. 5, 4943-4948(2011).

18) Wang, J. H.; Xu, L.; Yang, L.; Liu, Z. L.; Zhou, L. G. Composition, antibacterial and antioxidant activities of essential oils from Ligusticum sinense and L. jeholense (Umbelliferae) from China. Rec. Nat. Prod. 5, 314-318 (2011).

19) Huang, C. J. Flora of China. Vol. 43, Science Press, Beijing, China, pp. 155-161(1997).

20) Nanjing University of Chinese Medicine, Traditional Chinese Medicine Dictionary. Shanghai Science \& Technology Press, Shanghai, China, pp. 892 (2005).

21) Panda, H. Handbook on Medicinal Herbs with Uses. Asia Pacific Business Press Inc, pp. 166-167 (2004).

22) Luthria, D. L.; Ramakrishnan, V.; Verma, G. S.; Prabhu, B. R.; Banerji, A. Insect antifeedants from Atalantia racemosa. J. Agric. Food Chem. 37, 1435-1437 (1989).

23) Arnon, C.; Chanita, P.; Chatchanok, K.; Supinya, T. Potential anti-allergic acridone alkaloids from the roots of Atalantia monophylla. Phytochemistry 69, 26162620 (2008).

24) Baskar, K.; Kingsley, S.; Vendan, S. E.; Paulraj, M. G.; Duraipandiyan, V.; Igancimuthu, S. Antifeedant, larvicidal and pupicidal activities of Atalantia monophylla (L) Correa against Helicoverpa armigera Hubner (Lepidoptera: Noctuidae). Chemosphere 75, 355-359 (2009).

25) Pavithra, P. S.; Sreevidya, N.; Verma, R. S. A review of chemistry and biological activity of genus Atalantia (Rutaceae). J. Med. Aromatic Sci. 31, 63-72 (2009).

26) Reddy, K. H.; Sharma, P. V. G. K.; Reddy, O. V. S. A comparative in vitro study on antifungal and antioxidant activities of Nervilia aragoana and Atlantia monophylla. Pharm. Biol. 48, 595-602 (2010).

27) Baskar, K.; Muthu, C.; Raj, G. A.; Kingsley, S.; Ignacimuthu, S. Ovicidal activity of Atalantia monophylla (L) Correa against Spodoptera litura Fab. (Lepidop- 
tera: Noctuidae). Asian Pac. J. Trop. Biomed. 2, 987991 (2012).

28) Adams, R. P. Identification of Essential Oil Components by Gas Chromatography/Quadrupole Mass Spectro- scope. Allured: Carol Stream, IL, USA, (2001).

29) Laribi, B.; Kouki, K.; Mougou, A.; Marzouk, B. Fatty acid and essential oil composition of 3 Tunisian caraway (Carum carvi L.) seed ecotypes. J. Sci. Food Agric. 90, 391-396 (2010).

30) Samojlik, I.; Lakic, N.; Mimica-Dukic, N.; Dakovic-Svajcer, K.; Bozin, B. Antioxidant and hepatoprotective potential of essential oils of coriander (Coriandrum sativum L.) and caraway (Carum carvi L.) (Apiaceae). J. Agric. Food Chem. 58, 8848-8853 (2010).

31) Sakuma, M. Probit analysis of preference data. Appl. Entomol. Zool. 33, 339-347 (1998).

32) Chaubey, M. K. Insecticidal activity of Trachyspermum ammi (Umbelliferae), Anethum graveolens (Umbelliferae) and Nigella sativa (Ranunculaceae) essential oils against stored-product beetle Tribolium castaneum Herbst (Coleoptera: Tenebrionidae). Afr. J. Agr. Res. 2, 596-600 (2007).

33) Liu, Z. L.; Ho, S. H. Bioactivity of the essential oil extracted from Evodia rutaecarpa Hook f. et Thomas against the grain storage insects, Sitophilus zeamais Motsch. and Tribolium castaneum(Herbst). J. Stored Prod. Res. 35, 317-328(1999).

34) Das, A. K.; Swamy, P. S. Comparison of the volatile oil composition of three Atalantia species. J. Environ. Biol. 34, 569-571 (2013).

35) Manimaran, S.; Sathya, S.; Tamizhmani, T.; Subburaju, T.; Chinnaswamy, K.; Nanjan, M. J.; Suresh, B. Phytochemical investigation on leaf volatile oil of Atalantia monophylla Correa. Indian Perfumer 46, 341-342 (2002).

36) Chu, S. S.; Liu, S. L.; Liu, Q. Z.; Liu, Z. L.; Du, S. S. Composition and toxicity of Chinese Dracocephalum moldavica (Labiatae) essential oil against two grain storage insects. J. Med. Plants Res. 5, 5262-5267 (2011).

37) Li, W. Q.; Jiang, C. H.; Chu, S. S.; Zuo, M. X.; Liu, Z. L. Chemical composition and toxicity against Sitophilus zeamais and Tribolium castaneum of the essential oil of Murraya exotica aerial parts. Molecules 15, 5831-5839(2010).

38) Jiang, C. H.; Liu, Q. Z.; Du, S. S.; Deng, Z. W.; Liu, Z. L. Essential oil composition and insecticidal activity of Evodia lepta (Spreng) Merr. Root barks from China against two grain storage insects. J. Med. Plants Res. 6, 3464-3469 (2012).

39）Zhao, N. N.; Zhou, L. G.; Liu, Z. L.; Du, S. S.; Deng, Z. W. Evaluation of the toxicity of the essential oils of some common Chinese species against Liposcelis bostry- chophila. Food Control 26, 486-490 (2012).

40) Liu, X. C.; Zhou, L. G.; Liu, Z. L.; Du, S. S. Identification of insecticidal constituents of the essential oil of Acorus calamus Rhizomes against Liposcelis bostrychophila Badonnel. Molecules 18, 5684-5696 (2013).

41） Liu, Z. L.; Zhao, N. N.; Liu, C. M.; Zhou, L. G.; Du, S. S. Identification of insecticidal constituents of the essential oil of Curcuma wenyujin Rhizomes active against Liposcelis bostrychophila Badonnel. Molecules 17, 12049-12060 (2012).

42) Liu, Z. L.; Yu, M.; Li, X. M.; Wan, T.; Chu, S. S. Repellent activity of eight essential oils of Chinese medicinal herbs to Blattella germanica L. Rec. Nat. Prod. 5, 176-183 (2011).

43) Liu, Z. L.; Du, S. S. Fumigant components from the essential oil of Evodia rutaecarpa Hort unripe fruits. E-J. Chem. 8, 1937-1943(2011).

44) Iman, S.; Seyed Mehdi, H.; Ali, D. Fumigant toxicity of essential oil of Mugwort (Artemisia vulgaris L.) against three major stored product beetles. Arch. Phytopath. Plant Prot. 46, 445-450 (2013).

45) Ebadollahi, A.; Safaralizadeh, M. H.; Pourmirza, A. A.; Gheibi, S. A. Toxicity of essential oil of Agastache foeniculum (Pursh) kuntze to Oryzaephilus surinamensis L. and Lasioderma serricorne F. J. Plant Protect. Res. 50, 215-219(2010).

46) Nerio, L. S.; Olivero-Verbel, J.; Stashenko, E. Repellent activity of essential oils: a review. Biores. Technol. 101, 372-379 (2010).

47) Liu, Z. L.; Goh, S. H.; Ho, S. H. Screening of Chinese medicinal herbs for bioactivity against Sitophilus zeamais Mostchulsky and Tribolium castaneum (Herbst). J. Stored Prod. Res. 43, 290-296 (2007).

48) Jiang, Z.; Akhtar, Y.; Bradbury, R.; Zhang, X.; Isman, M. B. Comparative toxicity of essential oils of Litsea pungens and Litsea cubeba and blends of their major constituents against the cabbage looper, Trichoplusia ni. J. Agric. Food Chem. 57, 4833-4837 (2009).

49) Liu, Z. L.; Chu, S. S.; Jiang, G. H. Insecticidal activity and composition of essential oil of Ostericum sieboldii (Apiaceae) against Sitophilus zeamais and Tribolium castaneum. Rec. Nat. Prod. 5, 74-81 (2011).

50）Yang, K.; Wang, C. F.; You, C. X.; Geng, Z. F.; Sun, R. Q.; Guo, S. S.; Du, S. S.; Liu, Z. L.; Deng, Z. W. Bioactivity of essential oil of Litsea cubeba from China and its main compounds against two stored product insects. $J$. Asia-Pac. Entomol. 17, 459-466 (2014).

51) You, C. X.; Yang, K.; Wu, Y.; Zhang, W. J.; Wang, Y.; Geng, Z. F.; Chen, H. P.; Jiang, H. Y.; Du, S. S.; Deng, Z. W.; Liu, Z. L. Chemical composition and insecticidal activities of the essential oil of Perilla frutescens (L.) Britt. Aerial parts against two stored product insects. Eur. Food Res. Technol. 239, 481-490 (2014). 